\title{
Initial and continuing training of teachers mediating the development of educational practice: a historical-critical analysis
}

\author{
Formação inicial e continuada de professores mediando o \\ desenvolvimento da prática educativa: uma análise histórico-crítica
}

\section{Formación inicial y continua de profesores mediando el desarrollo de la práctica educativa: un análisis histórico-crítico}

\author{
Elayna Maria Santos Sousa ${ }^{1}$ (D), Eliana de Sousa Alencar Marques ${ }^{1}$ iD \\ ${ }^{1}$ Universidade Federal do Piauí, Teresina, Piauí, Brasil. \\ Autor correspondente: \\ Eliana de Sousa Alencar Marques \\ Email: esalencar123@ufpi.edu.br \\ Como citar: Sousa, E. M. S., \& Marques, E. S. A. (2021). Initial and continuing training of teachers mediating the \\ development of educational practice: a historical-critical analysis. Revista Tempos e Espaços em Educação, 14(33), \\ e13737. http://dx.doi.org/10.20952/revtee.v14i33.13737
}

\begin{abstract}
The article discusses results of research carried out with the aim of analyzing teachers' meanings about professional training, both initial and continuing. The research is based on the ideas of Vigotski and Espinosa about human development, in which two teachers who work in the municipal public network of Teresina-PI participated. The research instruments were a questionnaire and semi-structured interview. The analysis had the nuclei of meanings as a procedure. The analyzes indicate that, if, on the one hand, in the initial training, the appropriate knowledge helped in the professional development of the teachers, on the other hand, the continuing education has collaborated to keep them in a passive situation in the face of educational demands, because they remain dependent to tell them how to act professionally. The results also indicate that continuing education has the potential to remove teachers from the condition of passivity when it collaborates with the development of the conscience of this professional, in short, with their historical development.
\end{abstract}

Keywords: Historical development. Initial and continuing teacher training. Educational practices. Meaning and sense.

\section{RESUMO}

$\mathrm{O}$ artigo discute resultados de pesquisa realizada com o objetivo de analisar significações de professores sobre formação profissional, tanto inicial quanto continuada. A pesquisa é fundamentada nas ideias de Vigotski e Spinoza acerca de desenvolvimento humano, da qual participaram duas professoras que atuam na rede pública municipal de Teresina-PI. Os instrumentos 
de pesquisa foram questionário e entrevista semiestruturada. A análise teve como procedimento os núcleos de significação. As análises indicam que, se, por um lado, na formação inicial, os conhecimentos apropriados ajudaram no desenvolvimento profissional das professoras, por outro, a formação continuada tem colaborado para mantê-las em situação de passividade diante das demandas educacionais, porque permanecem na dependência de terceiros para lhes dizer como agir profissionalmente. Os resultados indicam, ainda, que a formação continuada tem o potencial de retirar professores da condição de passividade quando colabora com o desenvolvimento da consciência desse profissional, enfim, com seu desenvolvimento histórico.

Palavras-chave: Desenvolvimento histórico. Formação inicial e continuada de professores. Práticas educativas. Significado e sentido.

\section{RESUMEN}

El artículo analiza los resultados de la investigación realizada con el objetivo de analizar los significados de los docentes sobre la formación profesional, tanto inicial como continua. La investigación se basa en las ideas de Vigotski y Espinosa sobre el desarrollo humano, en la que participaron dos docentes que trabajan en la red pública municipal de Teresina-PI. Los instrumentos de investigación fueron un cuestionario y una entrevista semiestructurada. El análisis tuvo como procedimento los núcleos de significado. Los análisis indican que, si, por un lado, en la capacitación inicial, el conocimiento apropiado ayudó en el desarrollo profesional de los docentes, por otro lado, la educación continua ha colaborado para mantenerlos en una situación pasiva frente a las demandas educativas, porque siguen siendo dependientes para decirles cómo actuar profesionalmente. Los resultados también indican que la educación continua tiene el potencial de sacar a los docentes de la condición de pasividad cuando colabora con el desarrollo de la conciencia de este profesional, en resumen, con su desarrollo histórico.

Palabras clave: Desarrollo histórico. Formación inicial y continua del profesorado. Prácticas educativas. Significado y sentido.

\section{INTRODUÇÃO}

Ao refletirmos sobre as questões que fundamentam a realização de práticas educativas desenvolvidas pelos professores na escola de educação básica, consideramos relevante abordar aspectos que contribuem para a realização de tais práticas. Nessa direção, escolhemos, dentre os muitos determinantes dessa realidade, a formação de professores, pois consideramos ser este um aspecto de extrema relevância nesse contexto. Interessa, nesse cenário, entender: quem são essas pessoas? Como elas significam os processos formativos? O que aprendem? Como vivenciam esses processos?

Foi partindo dessas questões que, nos anos de 2015 e 2016, desenvolvemos pesquisa envolvendo professores da rede pública municipal de Teresina-PI, que têm sido referência no desenvolvimento de práticas educativas consideradas bem-sucedidas. O objetivo da pesquisa foi analisar as significações produzidas pelos professores sobre seu percurso histórico de formação profissional, tanto a inicial quanto a formação continuada. Escolhemos estudar as significações produzidas no processo formativo dos professores por duas razões: a primeira delas, por considerarmos a formação profissional mediação necessária e determinante da qualidade da prática educativa que o professor desenvolve na escola; a segunda razão tem relação com a tese vigotskiana de que toda atividade humana é significada (Vigotski, 2010).

Além das razões apontadas acima, outra ainda se impõe: toda significação humana originase da nossa relação com o mundo, do modo como somos afetados pelas situações vividas e sentidas. Essa ideia vigotskiana tem relação com o pensamento de Spinoza (2008) sobre os afetos estarem na base do processo de constituição das ações humanas. 
Foram esses os fundamentos que orientaram a realização da pesquisa que ora discutimos neste artigo, o qual está dividido em três seções. Na primeira, apresentamos reflexões teóricas que colaboram para a compreensão do processo de formação humana com base na Psicologia HistóricoCultural em diálogo com a Filosofia de Spinoza, relacionando essa discussão com os processos formativos de professores. Na segunda, discorremos sobre a metodologia adotada na realização da pesquisa empírica que deu origem a este texto. Na terceira, analisamos e interpretamos os dados da pesquisa empírica que envolveu duas professoras de educação básica na cidade de Teresina.

Finalizamos com considerações que nos ajudam a entender que, durante a vivência formativa, sobretudo a inicial, os professores produzem significações que os ajudam no desenvolvimento profissional. Entretanto, com o passar do tempo, a formação continuada pode favorecer situação de passividade diante das demandas da realidade educacional se, em vez de ajudar os professores a se desenvolverem, os mantenha presos às fórmulas prontas, dependentes de terceiros para lhes dizer como agir profissionalmente. Nossa posição é pela defesa de que a formação continuada tem o potencial de retirar o professor da condição de agente passivo, quando colabora com o desenvolvimento da consciência desse profissional, enfim, com seu desenvolvimento histórico.

\section{Entendendo a constituição histórica do "ser professor" em formação inicial e continuada}

Antes de adentramos na explicação de como se dá o processo de constituição histórica do professor, sobretudo daquele que consegue realizar com êxito sua atividade de ensinar, achamos pertinente esclarecer o que estamos chamando de práticas educativas escolares bem-sucedidas.

Entendemos por prática educativa escolar tudo aquilo que o professor faz para concretizar o processo de ensino e aprendizagem. Essa prática revela o nível de conhecimento apropriado pelo professor e reflete a consciência que o docente possui acerca do trabalho que realiza. Marques (2014) entende por prática educativa o conjunto de ações planejadas socialmente que se efetivam em espaços intersubjetivos - a escola é um desses espaços - criando, assim, oportunidades de ensino e aprendizagem. Portanto, a atividade que o professor realiza na escola deve ter como intencionalidade favorecer aprendizagens que impulsionam o desenvolvimento cognitivo, social e afetivo dos alunos. Quando professores conseguem realizar essa intencionalidade, constitui-se, assim, o que identificamos como práticas educativas bem-sucedidas na escola.

Não obstante, realizar esse tipo de prática exige que o professor tenha acesso a determinadas condições objetivas e subjetivas. Reconhecemos que são muitas essas condições, dentre elas, as materiais, que podem estar relacionadas às condições de trabalho, condições salariais favoráveis, estrutura didático-pedagógica adequada, escolas bem montadas, jornada de trabalho, etc. Além das condições de natureza material, não podemos ignorar que as condições subjetivas também são essenciais para o desenvolvimento de prática educativa bem-sucedida, dentre elas, destacamos a formação profissional.

Merçon (2009), em sua leitura spinozana sobre os processos que formam os seres humanos, explica que estes se constituem por meio de uma trajetória complexa que envolve a relação intrínseca entre corpo e mente. A autora compreende a formação humana como experiências afetivas, cuja potência provém das relações com outros corpos, por meio das quais nossa potência de pensar, sentir e agir pode ser aumentada ou diminuída. Trazendo isso para o campo que envolve as formações inicial e continuada, significa dizer que o professor, como corpo e mente que está em relação permanente com outros corpos, não forma apenas conceitos e não produz somente saberes relativos ao campo de atuação, mas produz afetos que potencializam seu pensar, sentir e agir em ato. Isso acontece porque nossa relação com o mundo é sempre mediada pelo que sentimos (afeto) e compreendemos (intelecto).

Spinoza (2008) explica que um corpo pode ser afetado de várias maneiras que aumentam ou diminuem a potência humana. Isto posto, podemos supor que o encontro do professor com 
outros corpos (outros professores, conhecimentos, espaços formativos) pode produzir afecções capazes de aumentar ou diminuir a potência intelectual e afetiva desse profissional. $O$ aumento da potência é considerado pelo autor como afeto/paixão ativa, que impulsiona o homem a conhecer as causas que o levam a buscar seu desenvolvimento. Análoga à compreensão de Spinoza (2008), podemos supor que os afetos ativos produzidos nos processos formativos oportunizam ao professor a criação de possibilidades transformadoras da realidade educativa, fazendo com que ele abandone ideias confusas sobre a profissão, sobre ser professor; enfim, ideias que apenas contribuem para a desmotivação e a alienação da sua consciência.

E como seria o processo formativo como possibilidade de ajudar o professor a alcançar o máximo de desenvolvimento de sua potência de pensar e agir em atividade profissional? De acordo com Marques (2015), processos formativos fundamentados na racionalidade crítica e reflexiva elevam as chances de os professores alcançarem um desenvolvimento mais potente de sua consciência, porque é o tipo de formação profissional de base teórico-metodológica que promove o exercício permanente da crítica, a análise da realidade educacional, partindo do resgate da sua historicidade, conhecendo as causas constitutivas da realidade como totalidade concreta, bem como as condições pelas quais esta se forma e se desenvolve.

A formação inicial e continuada precisa se constituir em processo educativo que favoreça a educação de professores politicamente mais conscientes e mais comprometidos com a realidade social humana. Defendemos que as transformações capazes de provocar mudanças efetivas na atividade do professor passam pela assunção de nova lógica na formação desses profissionais. Não se trata de qualquer formação, mas, sobretudo, aquela pautada em nova racionalidade, que possibilite aos professores condições cognitivas e afetivas de fazer a leitura crítica da realidade, de se posicionar contra qualquer forma de discriminação ou injustiça social; de defender o direito inalienável à educação pública, laica e de qualidade; de refletir criticamente sobre as questões ligadas à sua profissionalidade, o que, consequentemente, pode contribuir com o desenvolvimento da capacidade criadora ao realizar, com elevado grau de consciência, sua atividade, o que só é possível por intermédio de consciência desenvolvida pelo exercício do pensamento crítico e pelo comprometimento com a transformação social.

Ao concebermos que os professores têm a responsabilidade de desenvolver práticas educativas que potencializem ao máximo a humanização das novas gerações, entendemos que a formação inicial e a continuada de professores precisam servir ao propósito de lutar contra a alienação, "[...] ajudar a decifrar os enigmas do mundo, sobretudo o estranhamento de um mundo produzido pelos próprios homens" (Sader, 2008, p. 17). Os professores precisam ser educados para a compreensão do mundo, para seu envolvimento com a realidade, pois ao compreenderem o mundo e o modo como ele se constitui, ao sentirem-se responsáveis pelos rumos da educação que realizam, entenderão o verdadeiro sentido do que significa assumir o compromisso de educar para a transformação e a emancipação da sociedade.

Nesse sentido, a formação de professores precisa passar por mudança radical. Ela precisa sair da perspectiva hegemonicamente instrumental, tecnicista e pragmática, para assumir outro sentido, o da práxis. Se, na atualidade, os cursos de formação de professores se voltam para a instrumentalização da prática, é preciso investir na formação humana desse docente, o que significa desenvolvimento da sua consciência. Nas palavras de Mészarós (2008, p. 65), educá-lo para “[...] a elaboração de estratégias apropriadas e adequadas para mudar as condições objetivas de reprodução, como para automudança consciente dos indivíduos chamados a concretizar a criação de uma ordem social metabólica radicalmente diferente". Em outras palavras, os professores precisam ser educados para compreender sua condição ontológica de produtores da realidade, sujeitos da práxis. Esse processo, longe de ser integralmente racional, é radicalmente afetivo, é produto da relação de sentido que se cria na vida com aquilo que se vive e torna-se significativo. 
Entendemos, assim, que a formação profissional, isto é, a formação inicial e a continuada irão mediar muitas das tomadas de decisões do professor em atividade. Portanto, se queremos pesquisar o processo de constituição histórica do professor, precisamos investigar como sua consciência sobre ser professor se constitui. E como fazer isso? De acordo com Vigotski (2010), pelo modo como as significações sobre ser professor, sobre atuar na docência e sobre comprometer-se com o pleno desenvolvimento de seus alunos são construídas pela mediação dos processos formativos. Com base nos aportes da Psicologia Histórico-Cultural, compreendemos que a atividade humana é a consciência em movimento, é a expressão de como o sujeito compreende o que faz, o significado e o sentido disso em sua vida.

O estudo da consciência do professor em atividade envolve o estudo da relação dialética das categorias significado e sentido. As significações (unidade entre significado e sentido) expressam a relação do professor com a totalidade social, com o que imagina, sente e faz em atividade. As significações sobre os processos formativos são, portanto, mediações que explicam o processo de constituição do professor. Na pesquisa que será relatada a seguir, essa relação será melhor esclarecida.

\section{PERCURSO METODOLÓGICO DA PESQUISA}

Em função do objetivo de analisar as significações produzidas por professores sobre seus percursos históricos de formação profissional, tanto a inicial quanto a continuada, realizamos pesquisa de natureza qualitativa com professoras que atuam na rede pública municipal de Teresina$\mathrm{PI}$, precisamente, na etapa da Educação Infantil. Participaram da pesquisa duas professoras que foram escolhidas por terem sido reconhecidas pela Secretaria Municipal de Educação como docentes que realizam projetos educativos bem-sucedidos na escola.

Os instrumentos utilizados para a realização da pesquisa empírica foram o questionário e a entrevista semiestruturada. De posse dos dados obtidos com os questionários, foi possível construir um perfil das participantes investigadas, para, em seguida, passarmos para a segunda etapa da pesquisa, que envolveu a realização de entrevistas semiestruturadas. Nesse recorte, analisamos os dados produzidos por uma das professoras pesquisadas.

Para análise das informações construídas na investigação, fizemos uso do procedimento analítico denominado Núcleo de Significação (NS), proposto por Aguiar \& Ozella (2013). Essa metodologia assenta-se sob os princípios da Psicologia Histórico-Cultural e do Materialismo Histórico Dialético, sendo essa a razão que justifica a nossa opção por esse procedimento analítico. Os Núcleos de Significação requerem o trabalho com a palavra e seu significado. Para os autores desse procedimento metodológico, é a partir da palavra significada que nos aproximamos dos conteúdos mais instáveis e fluidos da consciência humana - as zonas de sentido.

Os Núcleos constituem-se como expressão de um movimento analítico-interpretativo, tornando-se fundamentais para captar a articulação do pensamento do professor investigado e interpretar as mediações que constituem a sua consciência. Desse modo, neste texto, apresentaremos os resultados reunidos no Núcleo intitulado "Contribuição da formação inicial e da continuada para o desenvolvimento da atividade docente". Nesse núcleo, estão agrupados indicadores que explicam de que modo a formação docente possibilitou o desenvolvimento de uma atividade bem-sucedida. Respeitando o direito de anonimato da profissional pesquisada, atribuímos a ela o nome de "Olívia".

\section{Contribuição da formação inicial e da continuada para o desenvolvimento da atividade docente}

O uso do procedimento Núcleos de Significação exige o cumprimento de algumas etapas no movimento de análise. Essas etapas são: 1) seleção de pré-indicadores; 2) levantamento de indicadores; e 3) constituição de núcleos de significação. Como essas etapas acontecem? 
De posse dos dados da entrevista, realizamos leituras sucessivas que nos permitiram identificar palavras ou trechos da narrativa que mostravam relação com o objetivo de analisar as significações produzidas pelas professoras sobre seu percurso histórico de formação profissional, tanto a formação inicial quanto a continuada. Essas palavras ou trechos são chamados de préindicadores. A identificação dos pré-indicadores é a primeira etapa no processo de análise. De acordo com Marques (2014), os pré-indicadores servem para indicar conteúdos relativos ao que o sujeito vive ou viveu e que podem ser ou terem sido determinantes no seu processo de desenvolvimento histórico.

Ao identificar e nomear esses conteúdos passamos para a segunda etapa no movimento de análise: agrupamento de indicadores. Os indicadores sintetizam os conteúdos que estão predominando nas entrevistas. Esses conteúdos são agrupados e recebem um nome que passa a figurar como indicador. Ao final desse agrupamento, procedemos com a análise e a interpretação desses conteúdos para formar os núcleos de significação, terceira etapa, que são nomeados em função dos sentidos que predominam no agrupamento de indicadores. São sentidos que mais se aproximam da consciência do sujeito pesquisado, porque revelam o movimento da vida, da história dessa pessoa, são elementos que, segundo Vigotski (2010), servem para ajudar na compreensão do mundo e no conjunto da estrutura psicológica do indivíduo.

No movimento de análise da entrevista de Olívia, após a seleção de pré-indicadores e o levantamento de indicadores, chegamos à constituição de três Núcleos de Significação. Neste texto, apresentamos as análises relativas ao Núcleo "Contribuição da formação inicial e da continuada para o desenvolvimento da atividade docente".

Neste Núcleo, desenvolvemos a discussão acerca dos seguintes indicadores: 1) Estágio possibilitando comparar teoria e prática e afirmação no curso de Pedagogia; 2) Contribuição das disciplinas pedagógicas para o desenvolvimento da docência na Educação Infantil; 3) Formação continuada como contribuição para o desenvolvimento do trabalho docente no ensino público.

No primeiro indicador deste Núcleo, "Estágio possibilitando comparar teoria e prática e afirmação no curso de Pedagogia", foi possível compreender que o estágio contribuiu de forma significativa para a produção de saberes docentes necessários à atividade profissional. Segundo a professora, a experiência foi rica, no sentido de oportunizar a percepção da realidade escolar, e de comparar a teoria estudada na universidade com a prática vivenciada na escola. A professora significa essa contribuição no trecho da entrevista:

A gente constatar que aquilo que a gente vê na universidade realmente está acontecendo (porque a gente tem esse negócio, né: comparar teoria com a prática)... E a gente sempre fazia nos estágios. Então, o curso me permitiu isso. Toda vez que eu ia para um estágio, eu constatava que eu tinha feito a escolha certa, e continuo achando (Dados da entrevista, grifos nossos).

De acordo com as significações expressas na narrativa, o estágio supervisionado de ensino, além de possibilitar à professora "comparar teoria e prática e enxergar a realidade nas escolas", permitiu também a confirmação de sua escolha pelo curso de Pedagogia como acertada. Se, antes, a professora tinha dúvidas, a reflexão acerca do processo vivido na formação inicial levou a docente a experimentar afeto de satisfação e segurança.

Durante muito tempo, as práticas de formação de professores eram norteadas por perspectivas que ora contemplavam a teoria, ora contemplavam a prática, fragmentando o desenvolvimento da profissionalidade do graduando, pois eram desprovidas de exercício crítico, empobrecendo a ação do professor no seu lócus de atuação.

Pimenta \& Lima (2012) consideram a ação do educador como uma prática social, pois a atividade docente torna-se ao mesmo tempo prática e ação. De acordo com as autoras, o professor se encontra em condição de sujeito determinado e determinante em relação às instituições de ensino. Dessa forma, para podermos entender a sua prática como social, precisamos nos atentar 
sempre para a relação entre ação e prática. É só mediante essa perspectiva que podemos ensejar processos educativos transformadores. Diante dessa questão, Pimenta \& Lima (2012, p. 42) esclarecem:

Em sentido amplo, ação designa a atividade humana, o fazer, um fazer efetivo ou a simples oposição a um estado passivo [...]. Assim, denominamos ação pedagógica as atividades que os professores realizam no coletivo escolar supondo o desenvolvimento de certas atividades materiais orientadas e estruturadas. Tais atividades têm por finalidade a efetivação do ensino e da aprendizagem por parte dos professores e alunos.

Esse debate supera a visão fragmentada acerca da formação docente, e a concebe de forma ressignificada, por meio do estágio supervisionado. A atividade de estágio na formação inicial, até pouco tempo atrás era considerada apenas em sua dimensão prática. Hoje, o debate atual ajuda a fortalecer sua dimensão teórica, a qual, aliada às teorias metodológicas e epistemológicas, contribuem para que a atividade docente se torne objeto da práxis, entendida esta como uma atividade que transforma a realidade.

Sob essa perspectiva, o estágio supervisionado, na sua dimensão teórica, tem a função de dar luz à atividade prática do professor, oferecendo instrumentos intelectuais adequados que permitem a problematização das práticas já incorporadas nos sistemas escolares. Para Vázquez (2007), os instrumentos intelectuais são potências que medeiam a relação que o homem estabelece com a natureza, revelando o desenvolvimento da sua força no trabalho e no domínio sobre a natureza.

A teoria construída em situação social de estágio supervisionado fundamenta o pensamento do professor na compreensão da educação como processo humano e histórico, determinado por causalidades e que somente pela articulação permanente da teoria com a prática é possível encontrar alternativas capazes de atender às demandas da escola e da sociedade. Desse modo, a teoria é tida como condição para o desenvolvimento de uma prática educativa contextualizada, favorecendo ao profissional docente saberes que o potencializam para uma visão mais sistêmica da realidade e, também, a efetivação dos instrumentos de ensino e aprendizagem, situando a ação prática em um contexto mais amplo. Ainda sobre isso, Pimenta \& Lima (2012, p. 111), acrescentam:

Ao transitar da universidade para a escola e desta para a universidade, os estagiários podem tecer uma rede de relações, conhecimentos e aprendizagens, não com o objetivo de copiar, de criticar apenas os modelos, mas no sentido de compreender a realidade para ultrapassá-la.

Durante a atividade de estágio na formação inicial, o graduando em formação para docência tem a oportunidade de analisar modelos e práticas de ensino de profissionais os quais lhes são relevantes. Essa experiência permite construir parâmetros que poderão favorecer a constituição de sua identidade profissional. Com o tempo, já na condição de profissional, o professor vai se desfazendo gradualmente de concepções pré-estabelecidas, construindo um modo de ser professor constituído nas e pelas relações com os seus pares e com o meio social.

Isso acontece porque o estágio contribui fortemente para a formação do professor possibilitando a construção da identidade docente, que reflete um estilo, um modo particular de ser profissionalmente. Para Pimenta \& Lima (2012), é na etapa da formação inicial que se consolidam as opções e os anseios para com a profissão, que se experimentam situações imprescindíveis à construção da identidade docente, e o estágio é a vivência que oportuniza ao professor em formação inicial entrar em contato com a realidade educativa, a qual se mostra rica em aprendizagens, possibilidades de superação de conflitos e confronto com as imprevisibilidades.

Sobre essa temática, Olívia ainda acrescenta: “[...] sempre fazia esse paralelo. Quando eu fui para o estágio [...], eu passei a enxergar mais ainda as disciplinas que eu pagava na universidade 
[...]" (grifos nossos). De acordo com a profissional, o estágio também ampliou seu olhar acerca das disciplinas ofertadas pelo curso de Pedagogia, motivando, assim, um modo de ser professor que realiza, por meio da intencionalidade educativa, metodologias de ensino voltadas para a objetividade do seu contexto escolar.

Sobre o exposto, inferimos que o contato com a realidade educacional proporcionada pelo estágio supervisionado durante a formação inicial afetou Olívia positivamente, de forma alegre, porque oportunizou que a então estudante pudesse enxergar-se como futura profissional da educação, impulsionando sentimento de pertencimento ao grupo docente. $O$ afeto de pertencimento levou a jovem estudante de Pedagogia a produzir sentido e significado sobre ser professora, sobre viver a educação numa perspectiva que ainda não havia sentido. Os afetos produzidos na relação com a experiência formativa aumentaram sua potência de ser e de sentir-se como professora.

No que se refere ao segundo indicador, denominado "Contribuição das disciplinas pedagógicas do curso para o desenvolvimento da atividade docente na Educação Infantil", verificamos que a docente pontuou duas disciplinas como marcantes na sua formação inicial como graduanda: Fundamentos da Educação Infantil e Didática da Alfabetização. Sobre isso, ela esclarece:

[...] a gente pagou uma disciplina muito legal, que foi Fundamentos da Educação Infantil... Que como eu estava em sala de aula na época, eu pude fazer muito esse paralelo, né... Ver o que estava dando certo, o que não estava dando certo. Então, a partir dessa disciplina, que eu acho que foi muito importante na minha formação, eu pude fazer essa comparação [...]. Então, eu sempre fazia esse paralelo [...]. (Dados da entrevista, grifos nossos).

Para Olívia, a disciplina de "Fundamentos da Educação Infantil" possibilitou vivenciar a experiência do estágio com mais eficácia, porque, segundo ela, a disciplina lhe proporcionou apropriações teóricas que favoreceram a objetivação de práticas mais conscientes na escola. A apropriação teórica a levava constantemente a relacionar o que aprendia na disciplina com o que fazia em sala de aula. Nessa disciplina, podemos supor que houve, segundo Spinoza (2008), um bom encontro, situação que acabou permitindo aumento da capacidade reflexiva e crítica acerca do processo educativo vivenciado na sua sala de aula.

Compreendemos que a preferência por essa disciplina se deve ao fato de proporcionar à professora produção de ideias adequadas sobre ser professora nessa etapa de ensino, o que mais adiante, em sua vida profissional, serviria de base para a atividade como docente na Educação Infantil. Sobre ideias adequadas, Spinoza (2008) esclarece que são elas que alteram positivamente nossa potência. Para o autor, "As ideias adequadas são aquelas que provêm do conhecimento que se produz de uma operação intelectual, na qual a mente humana deduz ideias de suas causas verdadeiras e não do seu encontro fortuito com as coisas ou do próprio acaso" (Spinoza, 2008, p. 33). Disso, deduzimos que a professora, em sua vivência na disciplina, produziu ideias adequadas sobre como ensinar e aprender na Educação Infantil, como mediar o ensino favorável ao desenvolvimento dos seus alunos. Essas ideias, construídas na formação inicial por ocasião da disciplina, ajudaram na expansão de sua consciência sobre a prática educativa nessa etapa do ensino.

Desse modo, a professora expandiu sua compreensão de modo que as reflexões promovidas na academia potencializam a prática pedagógica no espaço escolar. Olívia, afetada por bons encontros vividos no seu percurso de formação inicial no curso de Pedagogia, reconhece a importância da disciplina de Fundamentos da Educação Infantil, porque foi capaz de construir conhecimentos relacionados à história e às concepções sobre criança que permitem olhar mais analítico acerca da realidade na qual atua.

O professor em formação inicial pode, mediante o estudo dessa disciplina, entender que a Educação Infantil percorreu tortuosos caminhos, até se configurar no quadro atual. Hoje, amparada 
por bases legais, como a Constituição de 1988, o Estatuto da Criança e do Adolescente (1990), pela Lei Orgânica da Assistência Social (1993), e pela Lei de Diretrizes e Bases da Educação Nacional, de 1996, a Educação Infantil toma novos rumos, principalmente no que diz respeito à visão sobre infância (Horn, 2004). Hoje, a criança é tida como sujeito histórico, ativo, sujeito de vontades, e, por isso, necessita de educação que contemple sua subjetividade.

A reflexão da professora serve para fortalecer o debate acerca da importância da formação teórica nos cursos de licenciatura. A formação inicial precisa garantir aos graduandos a superação do senso comum e da visão positivista do conhecimento que tem servido para facilitar a aceitação acrítica da realidade. A formação inicial precisa colaborar para que os graduandos compreendam que a realidade social jamais é dada naturalmente, mas, antes, produzida historicamente. A formação inicial deve travar cotidianamente uma luta encarniçada contra o praticismo sedutor que leva milhares de professores a acreditarem que na prática não há teoria.

Apesar das práticas imediatistas desvinculadas de elementos teóricos ainda serem recorrentes na educação, a professora pesquisada revela um salto de qualidade no desenvolvimento de sua consciência, pois compreende que são as apropriações teóricas demandadas nas disciplinas estudadas que Ihes capacita para o trabalho na Educação Infantil.

Olívia também mencionou que a disciplina "Didática da Alfabetização" exerceu influência muito forte para o desenvolvimento das suas práticas educativas na escola municipal, como ela esclarece neste pré-indicador:

Didática da Alfabetização [...], que eu uso até hoje. Quando eu entrei na Prefeitura, foi a primeira coisa que me cobraram, porque aqui, na Prefeitura, a gente tem que avaliar os meninos do nivel I ao nível VI, de acordo com a Emília Ferreiro. Aí, eu, tam! Estudei isso [...]. (Dados da entrevista, grifos nossos).

Nessa significação, verificamos afeto de contentamento e segurança para atuar na rede pública municipal. Isso se dá mediante o esclarecimento de que o fundamento que embasa as práticas das escolas do município já era do seu conhecimento. Ou seja, a disciplina de "Didática da Alfabetização" conseguiu garantir à profissional apropriação adequada ao exercício da atividade docente na rede pública. Olívia revelou importância das reflexões promovidas por essas disciplinas para o trabalho mais consciente com seus alunos. Revelou ainda compreender que, diante da realidade tão contraditória e determinante, faz-se necessário que a prática reflexiva seja constantemente preocupação do professor, para que se possam plasmar práticas educativas bemsucedidas no ambiente escolar.

Em outra linha, a professora também coloca como disciplina importante para a efetivação da sua prática, a "Psicologia de Educação". Para ela, a disciplina foi fundamental para a compreensão dos alunos como seres subjetivos. Ela entende que essa disciplina se encontra aliada à disciplina de "Fundamentos da Educação Infantil", porque ambas visam "[...] entender a cabeça dos meninos, as teorias [...]".

Acreditamos que a profissional atribui importância à disciplina de Psicologia da Educação justamente por ela ser uma ciência que possibilita ao docente compreender o processo de ensino e aprendizagem como constituído por relações humanas e sociais. De acordo com Placco (2003), essa área do conhecimento é central quando se fala em Educação, porque está presente em todas as disciplinas de fundamentos e de metodologias que embasam o currículo do curso de formação inicial de professores.

Olívia sempre atuou na Educação Infantil, e, por esse motivo, enxergou nessas disciplinas importantes aliadas para o exercício crítico e reflexivo quanto à formulação de metas para o exercício de suas práticas. Entendemos que essas disciplinas foram importantes para ela, porque possibilitaram a expansão de significados e sentidos necessários para o bom andamento do trabalho com seus alunos em sala de aula. 
No terceiro indicador deste núcleo, que tem como título "Formação continuada como contribuição para o desenvolvimento do trabalho docente no ensino público", verificamos que a formação continuada possibilitou à professora o enfrentamento de dificuldades em sala de aula, como ela significa nos pré-indicadores que se seguem:

Assim que eu entrei na Prefeitura... Um mês foi a formação continuada. Aí, fiquei meio sem norte ainda. Elas passaram planejamentos para a gente... Aí, a partir do segundo... Aí, a gente foi levando as nossas angústias em sala de aula... E lá as professoras que fazem a nossa formação... Elas sempre tiravam as nossas dúvidas, sempre nos ajudavam... Eu saí de um nível de idade de seis anos e vim para cá com crianças da mesma idade... O conhecimento totalmente diferente. As crianças não sabiam sentar, não sabiam segurar em um lápis. Lá, as crianças do nível III sabem ler e escrever cursivo [...]. Então, quando a gente passou para a formação continuada... tudo foi se ampliando em termos de saber como ajudar as crianças a melhorarem suas aprendizagens. (Dados da entrevista, grifos nossos).

Como a professora assim significa, a formação continuada contribuiu para que ela se adaptasse o mais rapidamente à realidade do ensino público, isso porque a escola pública era novidade para ela, pois, anteriormente, exercia atividade como professora auxiliar em rede particular. A professora significa a formação continuada oferecida pelo Sistema Oficial ao qual está vinculada como "Uma maravilha na minha vida, assim que eu entrei, porque quando eu saí do colégio que eu estava e vim pra cá, o choque de realidade foi muito grande".

As significações produzidas por Olívia acerca da formação continuada demonstram também que esse tipo de formação está funcionando como processo que visa apresentar as soluções mais imediatas para os conflitos gerados na sala de aula. A professora, ao entrar em relação com a realidade da escola pública, a qual não conhecia, produz afetos de medo e insegurança que só serão superados com a formação continuada, com o exercício crítico acerca das condições concretas nas quais os sujeitos vivem e produzem suas necessidades. Não saber lidar imediatamente com as demandas que enfrenta no cotidiano docente é um dos afetos que integram o processo de constituir-se professora. Produzir necessidades em meio a novas realidades educacionais é intrínseco à realidade histórica de todos os professores, porque a realidade é movimento.

A docente explica que o choque de realidade se deu porque ela exercia sua atividade profissional em outro tipo de escola antes de ser aprovada em concurso público. O público com o qual a professora estava acostumada era bem diferente, tinha outras necessidades. Ela precisou vivenciar processos formativos nos quais suas necessidades como professora eram expostas, discutidas e problematizadas. É nesse sentido que a formação continuada de professores cumpre seu papel social.

Acostumada à rede privada de ensino, na qual as condições de trabalho permitem às crianças maiores oportunidades de se desenvolverem, a professora entrou em crise, ocasionada pela incerteza se conseguiria desenvolver seu trabalho do modo como entendia que era necessário, com a mesma qualidade com a qual estava acostumada. A formação continuada ajudou a professora a superar essa realidade, à medida que a fez compreender que, embora se tratando de realidades educativas diferentes, o que mais importava era o que ela precisava saber para atuar com segurança, responsabilidade e comprometimento. Nos trechos a seguir, ela evidencia as ações realizadas nessa formação:

Aqui na Prefeitura tem a formação continuada de quinze em quinze dias, que a gente recebe orientação para fazer planejamento; para desenvolver atividades diferenciadas para aquela criança que está com alguma dificuldade... [...]. E a nossa pedagoga sempre nos ajuda também em relação a encaminhar para o AEE... Trazer atividades diferenciadas... Não ficar no quadro lendo [...]. Eu também não gosto de transcrever, até porque é proibido, porque elas falam que 
não tem muita didática para a criança da Educação Infantil. Material em si, elas não davam, porque elas realmente não tinham... A gente tinha que construir esse material. Tipo, o aluno estava com dificuldades e a professora dizia: - Olha, faça assim, assim, assado! Elas mandavam moldes para a gente, e a gente fazia... E assim estava sendo. (Dados da entrevista, grifos nossos).

Como podemos observar, apesar de contribuírem com a professora em sua atuação profissional, as atividades contempladas pela formação continuada situam-se em nível instrucional e instrumental. As instruções e os manuseios de materiais para fins pedagógicos são etapas importantes e fazem parte do sentido orientador da formação continuada. Porém, não podem ser contempladas como um fim em si mesma.

A supervalorização da prática parte das necessidades de professores que se encontram justamente em desconformidade com sua realidade educativa, e reflete uma concepção pragmática acerca da sociedade e da educação. O tecnicismo, fruto da concepção instrumental ou pragmática, para Severino (2003), não visa o envolvimento dos professores com questões sociais, políticas ou filosóficas, pelo fato de considerá-las um desvio quanto à objetividade pragmática da formação docente. Diante disso, o autor infere:

Quando se tem em pauta a condição profissional do educador, pode-se afirmar que só será assegurada qualidade à sua atuação se, ao longo dos processos iniciais e continuados de sua formação, lhe for assegurado, pelas mediações pedagógicas, um complexo articulado de elementos formativos, produzidos pelo cultivo de sua subjetividade, que traduza competência epistêmica, técnica e científica, criatividade estética, sensibilidade ética e criticidade política. Será com uma prática guiada por referências dessa natureza que o profissional da educação poderá exercer sua função educativa no meio social, a partir de sua inserção num projeto educacional. (Severino, 2003, p. 87).

Para o autor, a formação continuada capaz de guiar o professor rumo ao seu desenvolvimento precisa articular elementos teórico-metodológicos da profissão com as questões sociais, políticas e culturais que constituem a complexidade do real. Essa condição ajuda os professores a atuarem mediante a realidade educacional que sempre se movimenta permeada por conflitos e imprevisibilidades.

A professora reconhece que as profissionais formadoras mais experientes colaboram para o desenvolvimento das suas práticas em seu percurso profissional. Entretanto, o que se pôde verificar foi que os processos formativos ainda estão voltados para ações que se reduzem ao nível do imediatismo. As práticas da formação continuada, de acordo com a narrativa da professora, encontram-se desprovidas de reflexões aprofundadas, impedindo que a docente compreenda a complexidade dos processos educativos como realidade que não se descola da totalidade social. A formação continuada reduz-se a um conjunto de orientações circunscritas ao praticismo pedagógico e não tem favorecido o desenvolvimento ético, político e humano da professora, porque as necessidades formativas são todas tratadas no campo do imediatismo.

Não podemos ignorar o fato de que a formação continuada tem contribuído para o exercício concreto de Olívia na docência, porque afeta a professora com a sensação de segurança. Por esse modo, não podemos deixar de apontar que mesmo vivenciando a formação continuada que colabora com sua atuação no plano mais imediato, a professora tem conseguido transformar aquilo que aprende nessa formação em possibilidades de ação que levam seus alunos a melhorarem cognitivamente, afetivamente e socialmente. $\mathrm{O}$ que queremos destacar é que seria mais frutífero se os processos de formação continuada, em sua totalidade, ajudassem a professora a aprender a refletir criticamente acerca da sua atuação, acerca da condição que seus alunos têm para se desenvolver, das necessidades concretas que enfrenta e das possibilidades que possam servir de 
alternativas ao enfrentamento de tais necessidades. Esse exercício sedimenta o desenvolvimento histórico da professora, porque coloca sua consciência em movimento.

A formação continuada cumpre seu papel de processo que colabora com o desenvolvimento profissional de professores quando cria essas possibilidades de análise e reflexão crítica do real. Não se trata de aprender com alguém sobre qual a melhor forma de ação, qual a melhor técnica a ser empregada, pois isto indica permanente estado de passividade. Os professores precisam assumir a condição de agentes ativos, o que requer educar-se para aprender a pensar criticamente acerca da realidade na qual se encontram, criar instrumentos simbólicos para agir em diferentes situações, educar-se para entender o movimento histórico da realidade e o que pode ser feito no sentido de ajudar os alunos e as alunas a encontrarem seu caminho no processo de aprendizagem e desenvolvimento.

Compreendemos que a formação continuada que guia o desenvolvimento dos professores como possibilidade de tirá-los da condição de passividade não se consubstancia nas respostas que apresenta aos professores, mas na possibilidade que cria quando colabora com a capacidade que esses docentes têm de aprender a refletir criticamente, tendo como substrato primário as condições objetivas e subjetivas em que realizam a prática educativa.

\section{CONSIDERAÇÕES FINAIS}

Os resultados alcançados com a realização da pesquisa relatada revelaram que a riqueza de aprendizagens e o confronto entre teoria e prática oportunizadas pelo estágio supervisionado na formação inicial exerceram forte influência na construção da identidade profissional de Olívia, ajudando a consolidar, assim, um modo singular de ser professora diante das inúmeras imprevisibilidades existentes no contexto educativo. O estágio supervisionado permitiu à Olívia a produção de afetos potentes de desenvolvimento, porque possibilitou que ela pudesse se reconhecer como profissional da educação num futuro bem próximo.

As significações expressas pela professora revelaram ainda que as disciplinas pedagógicas na formação inicial foram vivenciadas como bons encontros, porque se revelaram fontes de afetos de segurança e certeza do caminho que estava seguindo na sala de aula. Entretanto, em seu percurso histórico de formação e vivência da profissão, ela também experimentou afetos de insegurança, incerteza, medo, frustração quando se deparou com a realidade profissional com a qual ainda não se sentia preparada para atuar. Nesse momento histórico de seu desenvolvimento, a vivência da formação continuada devolveu à professora a sensação de bem-estar, de realização e segurança profissional.

Entretanto, não podemos deixar de destacar que o afeto de bem-estar, de satisfação e de segurança que a professora produz na relação com a formação continuada não ultrapassa a condição de conhecimento imaginativo, porque a distrai do verdadeiro sentido que deve ter esse processo em sua na vida profissional, que é o de produzir as condições para seu desenvolvimento histórico. Distraída pelos afetos de segurança e satisfação imediata, a docente continua atuando de forma passiva, pois depende de outras pessoas para orientar seu modo de agir. A decisão acerca do que fazer e de como fazer pertence a outros. A condição de passividade poderá ser superada quando a formação continuada for vivenciada com outra intencionalidade, como condição de desenvolvimento histórico. Desenvolver-se historicamente significa educar a consciência, aprender a analisar criticamente a realidade e encontrar o caminho da realização de práticas educativas potencialmente transformadoras da realidade.

Mediante as significações da professora, verificamos que mesmo a formação continuada tendo o caráter pragmático e imediatista, a docente produz afetos que geram sensação de segurança, o que funciona como potencializador de práticas concretas em sala de aula. Observamos que, em todo o percurso da professora, seja na formação inicial, na continuada ou nos estágios, ela pôde extrair os elementos positivos, ou seja, os afetos ativos de cada vivência. Inferimos, assim, que 
são essas as significações que estão mediando as práticas educativas que esta profissional desenvolve na instituição escolar na qual atua, que revelam não somente a singularidade da professora participante da pesquisa, mas também as particularidades da profissão docente que determinam e medeiam o desenvolvimento de muitos profissionais da educação.

Contribuições dos Autores: Sousa, E. M. S.: concepção e desenho, aquisição de dados, análise e interpretação dos dados, redação do artigo, revisão crítica relevante do conteúdo intelectual; Marques, E. S. A.: concepção e desenho, aquisição de dados, análise e interpretação dos dados, redação do artigo, revisão crítica relevante do conteúdo intelectual. As autoras leram e aprovaram a versão final do manuscrito.

Aprovação Ética: Não aplicável.

Agradecimentos: Não aplicável.

\section{REFERÊNCIAS}

Aguiar, W. M. J., \& Ozella, S. (2013). Apreensão dos sentidos: aprimorando a proposta dos núcleos de significação. Rev Bras Estud Pedagog, 94(236), 299-322.

https://www.scielo.br/i/rbeped/a/Y7jvCHjksZMXBrNJkqq4zjP/abstract/?lang=pt\#

Brasil. (1993). Lei no 8.742, 7 de dezembro de 1993. Lei Orgânica de Assistência Social (LOAS). Disponível em: http://www.planalto.gov.br/ccivil 03/leis/l8742.htm. (Acessado: 15.08.21).

Brasil. (1990). Lei n8.069, de 13 de julho de 1990. Dispõe sobre o Estatuto da Criança e do Adolescente e dá outras providências. Disponível em: http://www.planalto.gov.br/ccivil 03/leis/l8069.htm. (Acessado: 15.08.21).

Brasil. (1996). Lei no 9.394, de 20 de dezembro de 1996. Estabelece as Diretrizes e Bases da Educação Nacional. Disponível em: http://www.planalto.gov.br/ccivil 03/leis/l9394.htm. (Acessado: 15.08.21).

Constituição da República Federativa do Brasil. (1988). Presidência da República. 5 de outubro de 1988. Disponível em: http://www.planalto.gov.br/ccivil 03/Constituicao/Constituicao.htm. (Acessado: 15.08.21).

Horn, M. da G. S. (2004). Sabores, cores, sons, aromas: a organização dos espaços na Educação Infantil. São Paulo: ARTMED.

Marques, E. de S. A. (2015). Formação de professores bem-sucedidos: um processo de natureza crítica e reflexiva. In: Congresso Nacional de Educação - EDUCERE. Anais [...]: PUCPR, p. 21019-22029.

Marques, E. de S. A. (2014). O socioafetivo mediando a constituição de práticas educativas bem-sucedidas na escola. (Tese de Doutorado, Programa de Pós-Graduação em Educação da Universidade Federal do Piauí).

Merçon, J. (2009). Aprendizado ético afetivo: uma leitura spinozana da educação. Campinas, SP: Editora Alínea.

Mészarós, I. (2008). A educação para além do capital. São Paulo: Boitempo.

Pimenta, S. G., \& Lima, M. do S. L. (2012). Estágio e docência. São Paulo: Cortez.

Placco, V. M. N. de S. (2003). Psicologia da educação e prática docente: relações pessoais e pedagógicas em sala de aula? In: Tiballi, E. F. A., \& Chaves, S. M. (Org.). Concepções e práticas em formação de professores: diferentes olhares. Rio de Janeiro: DP\&A, 73-96.

Sader, E. (2008). Prefácio. In: Mészáros, I. (2008). A educação para além do capital. São Paulo: Boitempo.

Severino, A. J. (2003). Preparação técnica e formação ético-política dos professores. In: Barbosa, R. L. L. (Org.).

Formação de educadores: desafios e perspectivas. São Paulo: Editora UNESP, 71-90.

Spinoza, B. (2008). Ética. Belo Horizonte: Autêntica.

Vázquez, A. S. (2007). Filosofia da práxis. São Paulo: Expressão Popular, Brasil.

Vigotski, L. S. (2010). A construção do pensamento e da linguagem. São Paulo: Martin Fontes.

Recebido: 26 de maio de 2021 | Aceito: 22 de setembro de 2021 | Publicado: 09 de novembro de 2021 